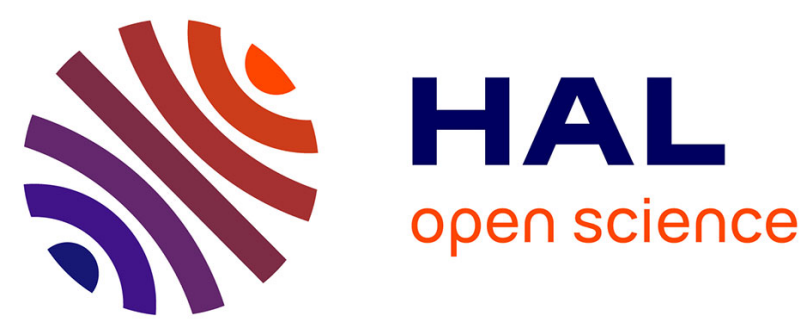

\title{
A Theoretical Study of the Wet Removal of Atmospheric Pollutants. Part V: The Uptake, Redistribution, and Deposition of (NM 4 ) 4 SO 4 by a Convective Cloud Containing Ice
}

Petra Respondek, Andrea I. Flossmann, R. Alheit, H. Pruppacher

\section{To cite this version:}

Petra Respondek, Andrea I. Flossmann, R. Alheit, H. Pruppacher. A Theoretical Study of the Wet Removal of Atmospheric Pollutants. Part V: The Uptake, Redistribution, and Deposition of (NM 4 ) $4 \mathrm{SO} 4$ by a Convective Cloud Containing Ice. Journal of the Atmospheric Sciences, 1995, 52 (11), pp.2121 - 2132. 10.1175/1520-0469(1995)0522.0.CO;2 . hal-01905567

\author{
HAL Id: hal-01905567 \\ https://hal.uca.fr/hal-01905567
}

Submitted on 3 Feb 2021

HAL is a multi-disciplinary open access archive for the deposit and dissemination of scientific research documents, whether they are published or not. The documents may come from teaching and research institutions in France or abroad, or from public or private research centers.
L'archive ouverte pluridisciplinaire HAL, est destinée au dépôt et à la diffusion de documents scientifiques de niveau recherche, publiés ou non, émanant des établissements d'enseignement et de recherche français ou étrangers, des laboratoires publics ou privés. 


\title{
A Theoretical Study of the Wet Removal of Atmospheric Pollutants. Part V: The Uptake, Redistribution, and Deposition of $\left(\mathrm{NH}_{4}\right)_{2} \mathrm{SO}_{4}$ by a Convective Cloud Containing Ice
}

\author{
Petra S. Respondek, A. I. Flossmann, * R. R. Alheit, ${ }^{\dagger}$ and H. R. Pruppacher \\ Institute of Atmospheric Physics, Johannes Gutenberg University, Mainz, Germany
}

(Manuscript received 26 April 1994, in final form 19 December 1994)

\begin{abstract}
The effects of an ice phase on the wet deposition of aerosol particles was studied by means of the authors' 2D cloud dynamics model with spectral microphysics applied to the Cooperative Convective Precipitation Experiment in Miles City, Montana, on 19 July 1981 . The cloud macrostructure as well as the cloud microstructure simulated by the model was found to agree well with observations. Although no on-site observations were available with respect to the chemical composition of the cloud and rain water, the values predicted by the model compared well with typical nearby measurements. The following conclusions can be derived from the model computations: (1) In confirmation of the authors' previous findings, derived from a parcel model, it was found that inside mixed ice-water clouds the aerosol mass becomes redistributed in such a way that the main aerosol mass is always associated with the main water or ice mass. (2) Since riming was the dominant growth mechanism of the hydrometeors in the cloud considered, the main aerosol mass - originally associated with the cloud drops via nucleation scavenging-became part of the graupel by riming. (3) In confirmation of earlier results for "warm" clouds, the scavenging efficiency of the cloud was found to be given within a few percent by the precipitation efficiency of the cloud system. (4) By purposely inhibiting ice nucleation but otherwise keeping all dynamic, thermodynamic, and microphysical input parameters the same, it could be shown that the changes in the microphysical structure of the cloud, which significantly altered both the time rainfall began and the rainfall duration, also significantly altered the wet deposition of chemical species. A careful consideration of the ice phase in cloud chemical modeling is therefore required.
\end{abstract}

\section{Introduction}

In a number of previous studies (Flossmann et al. 1985, 1987; Flossmann and Pruppacher 1988; Flossmann 1991, 1993, 1994) we have developed a cloud dynamics model with detailed spectral microphysics. The model allows us to compute the evolution of the dynamical, microphysical, and chemical characteristics of a convective cloud. In some earlier pilot studies (Flossmann et al. 1985, 1987) we used a simple air parcel model as the dynamic framework. More recently, we have used a dynamic framework consisting of a 2D slab symmetric model, which we adapted from Clark (1977, 1979), Hall (1980), Clark and Gall (1982), Clark and Farley (1984). Thus far, the work has dealt with warm clouds; that is, the ice phase was

\footnotetext{
* Current affiliation: Universite Blaise Pascal, Clermont-Ferrand, France.

${ }^{\dagger}$ Current affiliation: DLR, Institute of Atmospheric Physics, Oberpfaffenhofen, Germany.
}

Corresponding author address: Prof. H. R. Pruppacher, Institut fur Physik Der Atmosphare, Fachbereich Physik, Johannes Gutenberg-Universitat Mainz, Becherweg 21, Mainz 55099, Germany. E-mail: responde@goofy.zdv.uni-mainz.de not considered, with the exception of one pilot study (Alheit et al. 1990) that investigated the effect of the ice phase on the scavenging of aerosol particles by using an air parcel model. The latter study suggested that the scavenging of aerosol particles is significantly affected by the presence of an ice phase.

We, therefore, included in the present study the ice phase in our 2D model. In particular, we attempted to investigate the significance of an ice phase on microphysics and scavenging properties of a cloud by purposely inhibiting the appearance of an ice phase in the model. In order to compare our computations with observations, we chose as input for our model the temperature and humidity sounding that was obtained during the Cooperative Convective Precipitation Experiment (CCOPE) on 19 July 1981 in Miles City, Montana. The atmospheric conditions on that day were quite favorable for the development of cumulus convection, which due to relatively weak shear led to rather small individual storms with limited precipitation. The meteorological and cloud microphysical conditions on that day were well documented by Dye et al. (1986) and by a WMO (1988) report. Other authors (e.g., Taylor 1989a,b; Murakami 1990; Helsdon and Farley 1987) have simulated the same case. Although their models have a 2D or 3D dynamics, they only contain a bulk parameterization for the microphysics. 


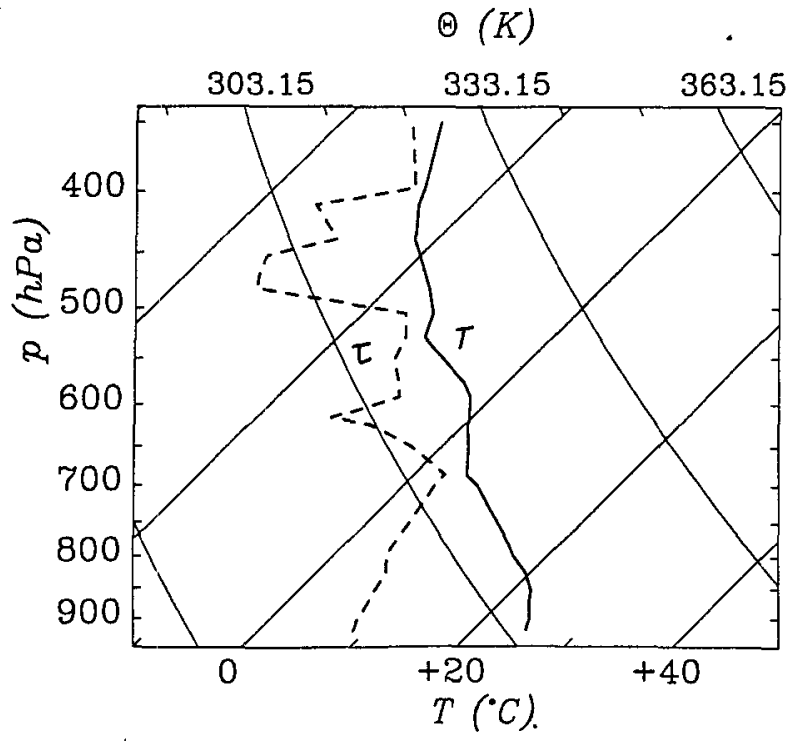

FIG. 1. Temperature (solid line) and dewpoint (dashed line) profile on 19 July 1981 over Miles City, Montana, as used as model input (lower part was modified, see text).

Detailed size distributions of aerosol particles (AP) and their chemical composition were available for the geographic site but unfortunately not for the specific date (Hobbs et al. 1985) and could be used as input in our model. Also, no chemical analysis of cloud and rain water was available for that day and location, so that for our scavenging module no quantitative comparison between theory and observation was possible.

In the following sections we give a brief description of the model and its initialization. Subsequently, the results of the simulation are presented and compared both with the observations and with the results of other models that studied the same case. Finally, we present the results for a model run during which the ice phase was intentionally inhibited. The results of this run were used to study the effects of an ice phase on the dynamics, the microphysics, and the scavenging properties of a cloud. The paper concludes by computing the total material involved in the various scavenging processes and the pertinent scavenging efficiencies.

\section{The present model}

The dynamic framework of our 2D model has been already discussed in detail by Flossmann and Pruppacher (1988) and Flossmann (1991), while the details of the spectral microphysics used in the present model have been discussed in Flossmann et al. (1985) and Alheit et al. (1990). In order to avoid redundancy and considering the rather lengthy description needed for all the microphysical mechanisms included in the model, we shall only highlight a few important points here. For the complete information we refer the reader to the above-mentioned publications.
As in Flossmann and Pruppacher (1988), the present model computes the time rates of change of the number density distribution function of aerosol particles in air $f_{A P a}\left(m_{A P}\right)$; the mass density distribution function of the aerosol particle mass $g_{A P_{a}}\left(m_{A P}\right)$ in air; the number density distribution function of drops $f_{d}(m)$; and the mass density distribution function of the aerosol mass in the cloud drops $g_{A P d}(m)$, where $m_{A P}$ is the mass of an aerosol particle and $m$ is the mass of a drop.

Following Alheit et al. (1990) and Alheit (1991), the present model also computes the time rates of change of the number and mass density distribution functions of the ice crystals $f_{i}\left(a_{i}\right), g_{i}\left(a_{i}\right)$, respectively; the mass density distribution functions of the aerosol mass captured by the ice crystals $g_{A P_{i}}\left(a_{i}\right)$; and the corresponding values for the graupel $f_{g}\left(a_{g}\right), g_{g}\left(a_{g}\right)$ and $g_{A P g}\left(a_{g}\right)$, where $a_{i}$ is the radius of the assumed platelike ice crystals and $a_{g}$ the radius of the graupel.

However, not all microphysical variables involved in describing the growth of the cloud and precipitation particles can be predicted by our model. In this sense, our model is partly diagnostic and requires some assumptions. Thus, in the present model, which also considers the melting of the graupel and ice crystals, the ice crystals are assumed to melt instantaneously to drops once the air temperature had risen above $0^{\circ} \mathrm{C}$. During melting the aerosol material scavenged by the ice crystals is assumed to remain captured and thus adds to the $A P$ mass inside the drops. The melting rate of the graupel is computed according to the method proposed by Rasmussen and Heymsfield (1987a,b). Also for these particles it is assumed that the aerosol material scavenged by the graupel remains inside the graupel during melting and inside the drops once the graupel have completely melted. In addition, rimed ice crystals are assumed to become graupel if the axis ratio calculated from their radius and thickness exceeds 0.25 or if a drop larger than $180 \mu \mathrm{m}$ in diameter freezes by contact nucleation with ice crystals. In addition, graupel are generated by heterogeneous drop freezing following the relation of Bigg ( see Chapter 9 in Pruppacher and Klett 1978), wherein the constants assume the values determined experimentally by Barklie and Gokhale (1959) for drops of rainwater. The values for the collision efficiencies of supercooled water drops and ice crystals recently computed by Wang and $\mathrm{Ji}$ (1992) were used. The efficiencies for the collision of drops with graupel and the efficiencies with which aerosol particles are captured by drops, graupel, and ice crystals are those used by Alheit et al. (1990).

\section{Initial conditions}

The present model was initialized by a sounding taken at 1440 mountain daylight time (MDT) on 19 July 1981 over Miles City. Considering the analysis of aircraft data by Helsdon and Farley (1987), we decided to reduce the moisture in the below-cloud region (Fig. 
1). The general weather condition on 19 July was characterized by a weak high pressure system, allowing the development of small isolated convective cells. The particular cloud studied from airplanes by Dye et al. (1986) formed shortly after 1600 MDT. Our 2D model domain was oriented into the main wind direction $\left(300^{\circ}\right)$. In the lower $1.5 \mathrm{~km}$ the wind came mainly from ENE and aloft from WNW. The wind speeds were set to $50 \%$ of their original values in order to prevent the model cloud from leaving the model domain too rapidly.

The aerosol particle spectrum observed by Hobbs et al. (1985) for the same geographic location was fitted by superimposing three lognormal distributions:

$$
\begin{aligned}
& \frac{d N_{A P a}}{d \ln r_{N}}= f_{A P a}\left(\ln r_{N}\right) \\
&=\sum_{i=1}^{3} f_{A P a, i}\left(\ln r_{N}\right)=\sum_{i=1}^{3} \frac{n_{i}}{(2 \pi)^{1 / 2} \log \sigma_{i} \ln 10} \\
& \quad \times \exp \left(-\frac{\left[\log \left(r_{N} / R_{i}\right)\right]^{2}}{2\left(\log \sigma_{i}\right)^{2}}\right),
\end{aligned}
$$

where $r_{N}$ is the dry aerosol particle radius. The resulting parameters of these distributions are given in Table 1 . Comparisons between the observed and fitted number and volume distribution are made in Fig. 2. The composition of the aerosol particles was assumed to be that observed for the High Plains (Hobbs et al. 1985) and to consist of $22 \%\left(\mathrm{NH}_{4}\right)_{2} \mathrm{SO}_{4}$ and $78 \%$ water insoluble silicate, whose specific gravity was assumed to be 2 $\mathrm{g} \mathrm{cm}^{-3}$. The silicate portion of the aerosol particle was assumed to be the ice-initiating compound. We further assumed that the aerosol particles were homogeneously distributed within the lowest $2 \mathrm{~km}$ of the atmosphere. Above $2 \mathrm{~km}$ the concentration was assumed to decrease according to

$$
\begin{aligned}
f_{A P a}\left(\ln r_{N}, z\right. & >2 \mathrm{~km}) \\
& =f_{A P a}\left(\ln r_{N}, z=2 \mathrm{~km}\right) \cdot \exp ^{-\left(z-z_{g}\right) / H},
\end{aligned}
$$

where $z$ is the height above ground in the model, $z_{g}=2$ $\mathrm{km}$, and scale height $H=2 \mathrm{~km}$.

The present model covered a domain of $15 \mathrm{~km}$ in the vertical and $30 \mathrm{~km}$ in the horizontal. The grid spacings were $\Delta z=250 \mathrm{~m}$ and $\Delta x=600 \mathrm{~m}$, and the time step was $\Delta t=5 \mathrm{~s}$ before cloud formation and $2 \mathrm{~s}$ afterward.

The dynamic model of Clark and collaborators, which we used for our model study, was driven by a sensible and latent heat flux from the surface following the formulations by Clark and Gall (1982) and the parameterized version of the calculations of Smolarkiewicz and Clark (1985), as described in Flossmann and Pruppacher (1988). As in their studies, we assumed that the fluxes were proportional to the incoming solar flux. The average surface sensible heat flux was assumed to be $35 \%$ of the incoming solar flux and the
TABLE 1. Parameters for the aerosol particle distribution assumed, as given in Eq (1); $n_{i}=$ total number of aerosol particles per $\mathrm{cm}^{-3}$ $R_{i}=$ geometric mean aerosol particle radius in $\mu m, \sigma_{i}=$ standard deviation in mode.

\begin{tabular}{clll}
\hline \hline Mode $i$ & $n_{i}$ & $R_{i}$ & $\log \sigma_{i}$ \\
\hline 1 & 40000 & 0.006 & 0.300 \\
2 & 3980 & 0.030 & 0.300 \\
3 & 0.3 & 1.000 & 0.396 \\
\hline
\end{tabular}

latent heat flux to be $0.5 \%$ of the incoming solar flux. These fluxes were considered to consist of a background heat flux and a perturbation fraction with a Gaussian spatial distribution. It was assumed that 99.9\% of the total energy went into Gaussian perturbation of sensible heat flux, while $0.1 \%$ of the total energy went into the Gaussian perturbation of the latent heat flux. We further set the half-widths of both Gaussian perturbations to be $7200 \mathrm{~m}$. The maximum of heating was located at $x_{0}=12.9 \mathrm{~km}$ during the first $45 \mathrm{~min}$ of modeling time. The heat and moisture sources were assumed to have their maximum value at the ground and to decrease exponentially with height, so that at $150 \mathrm{~m}$ their strength was $1 / e$ of their surface values.

In order to model the dynamic features of the cloud, $x_{0}$ was shifted after $45 \mathrm{~min}$ of modeling time from $x_{0}$ $=12.9 \mathrm{~km}$ to $x_{0}=15 \mathrm{~km}$, while the sensible heat flux at the same time was increased from $35 \%$ to $60 \%$ of the incoming solar flux. This was done to account for the observed conditions for cloud formation (based on a motion picture obtained from J. Dye) that favored the formation of small cumuli yet allowed the formation of isolated, precipitating clouds over restricted portions of the terrain. At model time $t=75 \mathrm{~min}$ the heating source was then reduced to the background heat flux. This was done to account for the shading of the cloud, which at that time had an age of $20 \mathrm{~min}$. The rate and duration of heating were chosen to represent a cloud that formed over dry ground and was advected with the mean wind to a hot surface where it intensified.

The computations were carried out on a CRAY Y$\mathrm{MP} / 232$ at the (Deutsche Forschungsanstalt für Luftund Raumfahrt), Oberpfaffenhofen, Germany. One model run (130-min simulation time) took $12 \mathrm{~h}$ of computer time.

\section{Results and discussion \\ a. General development of the model cloud}

Our calculations were started at 1505 MDT. The surface sensible and latent heat flux caused the air to rise, so that at 1600 MDT (cloud lifetime $t_{w}=0 \mathrm{~min}$ ) a cloud had formed with a base near $3.5 \mathrm{~km}$ ASL. (Note that in all the forthcoming diagrams and tables the altitude, ASL, is given by $z+0.8 \mathrm{~km}$, where $z$ is the model height above ground and $0.8 \mathrm{~km}$ the elevation of Miles City above sea level.) 


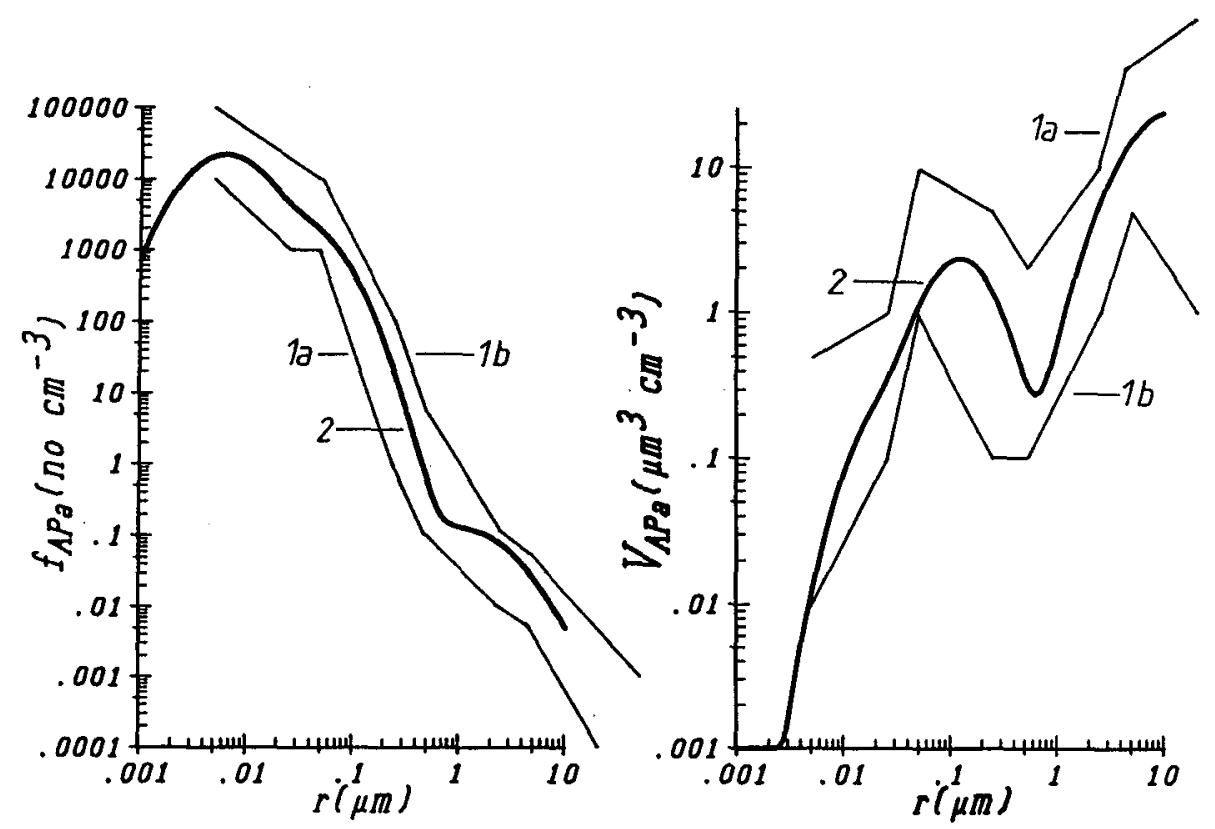

Fig. 2. Aerosol number (left) and volume distribution (right) for High Plains as observed by Hobbs et al. (1985) (curves 1a,b) and as used in the model resulting from Eq. (1) (curve 2).

During the first $20 \mathrm{~min}$ of its lifetime the model cloud experienced a moderate growth rate with maximum vertical velocities varying between 7 and $10 \mathrm{~m} \mathrm{~s}^{-1}$ at $5.3 \mathrm{~km}$ ASL, while the cloud top rose from 4.3 to 7.3 km ASL.

A vigorous growth phase of the model cloud began at about $1621 \mathrm{MDT}\left(t_{w}=21 \mathrm{~min}\right)$ and lasted until about 1633 MDT followed by a rapid weakening of the updraft (Fig. 3a). The overall maximum vertical velocity of $16.5 \mathrm{~m} \mathrm{~s}^{-1}$ occurred at $6.8 \mathrm{~km}$ ASL at 1625 MDT. By the end of this growth phase the cloud top reached its highest level of $11 \mathrm{~km} \mathrm{ASL}$, and subsequently, the upper growth region shifted toward the downshear side of the cloud forming a small anvil dominated by ice crystals.

During the period of moderate growth (up to 1621 MDT) the cloud consisted mainly of liquid hydrometeors, although the cloud-top temperature was about $-20^{\circ} \mathrm{C}$. With onset of the rapid growth phase, the iceforming processes (heterogeneous drop freezing and subsequently riming of ice particles) initiated a decrease in the liquid water content ("dry out") (Fig. 3a). The maximum liquid water content of $6.61 \mathrm{~g} \mathrm{~kg}^{-1}$ in the entire model domain was found at $6-6.6 \mathrm{~km}$ ASL at 1623 MDT (Fig. 3a). A second maximum at 1639 MDT resulted from a small secondary cloud at $\approx 5 \mathrm{~km}$ ASL that had originally formed around $X=13 \mathrm{~km}$ (the place same where the primary cloud originated) at $1625 \mathrm{MDT}\left(t_{w}=25 \mathrm{~min}\right)$ and was advected with the wind. As with the main cloud, this secondary cloud underwent liquid dry out within a few minutes, since falling graupel from above eroded away its liquid portions by riming. This can be seen in the increase of the graupel mass content at that time (Fig. 3b). Liquid dry out of the visible cloud in the model started at 1629 MDT and was completed around 1645 MDT. At 1621 MDT (just before the rapid growth phase), the drop concentration in the model cloud had reached $572 \mathrm{~cm}^{-3}$ at a level of $6.2 \mathrm{~km}$ ASL. The maximum number concentration of drops with radii less than $30 \mu \mathrm{m}$ was found to be $762 \mathrm{~cm}^{-3}$ in the secondary cloud at 1633 MDT at $4.2 \mathrm{~km} \mathrm{ASL}$, but the average maximum value was about $500-$ $600 \mathrm{~cm}^{-3}$ decreasing to lower values toward the end of the simulation.

Until the beginning of the rapid growth phase, no graupel were predicted by the model. The first graupel appeared in the simulation at $5.8 \mathrm{~km}$ ASL at $1623 \mathrm{MDT}$ with a maximum concentration of $0.01 \mathrm{~L}^{-1}$. The overall maximum graupel concentration of $120 \mathrm{~L}^{-1}$ was found at 8.2-8.6 km ASL at 1629 MDT, while the maximal graupel mixing ratio of $8.89 \mathrm{~g} \mathrm{~kg}^{-1}$ was located at $6.8-8 \mathrm{~km}$ ASL (Fig. 3b), indicating the presence of larger and heavier graupel in lower levels. A second maximum at 1641 MDT occurred when graupel from aloft fell into the secondary cloud and removed the liquid portions via riming.

Moderate rain, resulting mostly from completely melted graupel, began to reach the ground around 1645 MDT and lasted till about 1710 MDT. A negligible portion of this precipitation consisted of partly melted graupel. 

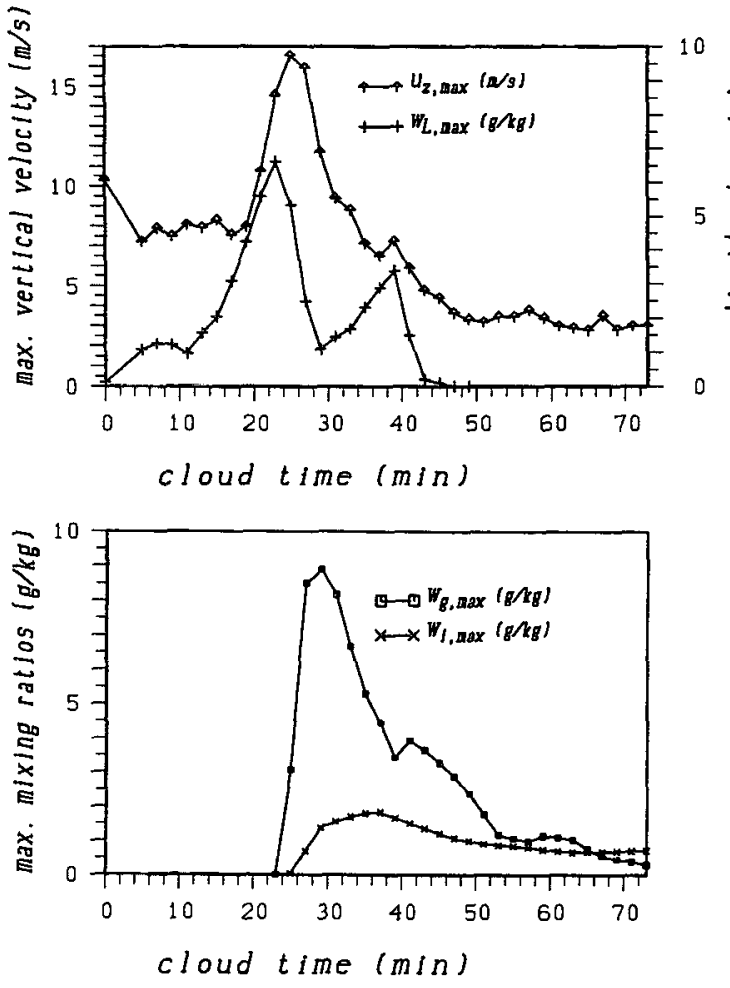

Fig. 3. Maximal (a) vertical velocity $u_{\max }\left(\mathrm{m} \mathrm{s}^{-1}\right)$ and mixing ratio $w_{L \max }$ $\left(\mathrm{g} \mathrm{kg}^{-1}\right)$ and (b) mixing ratios $\left(\mathrm{g} \mathrm{kg}^{-1}\right)$ of ice crystals $w_{i, \max }$ and graupel $w_{g, \max }$ as function of cloud lifetime $(\min )\left(t_{w}=0 \mathrm{~min}\right.$ at $\left.1600 \mathrm{MDT}\right)$.

\section{b. Comparison of model results with observations}

Tables 2a,b summarize the model cloud characteristics mentioned in the previous section and compare them with observations of Dye et al. (1986) involving measurements that have been made between $5.2 \mathrm{~km}$ and $6.0 \mathrm{~km}$ ASL by the research aircraft "King Air" and by a sailplane that made a spiral ascent from 3.9 $\mathrm{km}$ ASL (cloud base) to $7.2 \mathrm{~km}$ ASL in the main updraft region of the cloud. These measurements were carried out between 1617 and 1651 MDT.

From Table 2a, we note that most of the dynamic features of the observed cloud have been well reproduced by the model cloud with the exception, perhaps, of the cloud base and the beginning of the liquid dry out. Thus, our model cloud formed its base at $3.5 \mathrm{~km}$ ASL, which is slightly lower than the observed base at $3.9 \mathrm{~km}$ ASL. This is a result of the fact that the boundary layer was drier than indicated by the rawinsonde values that we used, a feature noted by Helsdon and Farley (1987). It demonstrates the requirement to have in situ measurements of the vertical structure of thermodynamic parameters.

During the first 20 min of cloud lifetime, the cloudtop height rose with a mean rise rate of $3 \mathrm{~m} \mathrm{~s}^{-1}$ up to $7.3 \mathrm{~km}$ ASL, which agrees with the cloud top given by Dye et al. (1986). The King Air flying at a level of 6
TABLE 2a. Comparison of model results with the observations of Dye et al. (1986)-general cloud appearance; altitudes are given in km ASL, times in MDT.

\begin{tabular}{|c|c|c|}
\hline Feature & Model & Observartion \\
\hline Cloud base (km) & 3.5 & 3.9 \\
\hline $\begin{array}{l}\text { Height of cloud top } \\
(\mathrm{km})\end{array}$ & $\begin{array}{l}\text { at } 1615 \mathrm{MDT} \\
6.0-6.5 \\
\text { at } 1625 \mathrm{MDT} \\
10.2-10.6\end{array}$ & $\begin{array}{l}6 \\
10.5\end{array}$ \\
\hline Mean cloud diameter & $6 \mathrm{~km}$ & $6 \mathrm{~km}$ \\
\hline Updraft width & $2 \mathrm{~km}$ & $2 \mathrm{~km}$ \\
\hline $\begin{array}{l}\text { Start of vigorous } \\
\text { growth phase }\end{array}$ & $1621 \mathrm{MDT}$ & $1623 \mathrm{MDT}$ \\
\hline $\begin{array}{l}\text { Vertical velocity } \\
\left(\mathrm{m} \mathrm{s}^{-1}\right)\end{array}$ & $\begin{array}{l}\text { at } 1620 \mathrm{MDT} 4 \\
\mathrm{~m} \mathrm{~s}^{-1} \text { at } 6 \mathrm{~km} \\
16.5 \text { at } 6.8 \mathrm{~km} \\
\text { and } 1625 \mathrm{MDT}\end{array}$ & $\begin{array}{l}3-5 \mathrm{~m} \mathrm{~s}^{-1} \text { at } 6 \mathrm{~km} \\
15 \text { at } 6.5-7 \mathrm{~km} \\
\text { and } 1627 \mathrm{MDT}\end{array}$ \\
\hline $\begin{array}{l}\text { Mean rise rate of } \\
\text { cloud top }\left(\mathrm{m} \mathrm{s}^{-1}\right)\end{array}$ & $5-6$ & $5-7$ \\
\hline $\begin{array}{l}\text { Beginning of updraft } \\
\text { decay }\end{array}$ & $1627-1629 \mathrm{MDT}$ & $1632-1634 \mathrm{MDT}$ \\
\hline Liquid dry out (start) & 1629 MDT & 1632 MDT \\
\hline Finished & 1645-1650 MDT & $1645 \mathrm{MDT}$ \\
\hline Max rainfall rate & 1655-1710 MDT & $1655-1700 \mathrm{MDT}$ \\
\hline
\end{tabular}

$\mathrm{km}$ ASL measured at that time a vertical velocity of 3$5 \mathrm{~m} \mathrm{~s}^{-1}$, which compares well with the $4 \mathrm{~m} \mathrm{~s}^{-1}$ velocity simulated by the model.

TABLE 2b. Comparison of model results with the observations of Dye et al. (1986) - distribution of hydrometeors; altitudes are given in $\mathrm{km}$ ASL, times in MDT.

\begin{tabular}{|c|c|c|}
\hline Feature & Model & Observation \\
\hline \multirow{4}{*}{$\begin{array}{l}\text { Liquid water content } \\
\text { at } 6 \mathrm{~km}\left(\mathrm{~g} / \mathrm{m}^{3}\right)\end{array}$} & 1.78 at $1621 \mathrm{MDT}$ & $1-1.75$ \\
\hline & 2.3 at $1625 \mathrm{MDT}$ & 2.2 \\
\hline & 0.24 at $1629 \mathrm{MDT}$ & 2.2 at 1627 MDT \\
\hline & 0.04 at 1643 MDT & 0.04 at $1643 \mathrm{MDT}$ \\
\hline \multirow{2}{*}{$\begin{array}{l}\text { Drop number } \\
\text { concentration } \\
\left(\mathrm{cm}^{-3}\right)\end{array}$} & $\begin{array}{l}572 \text { at } 1621 \text { MDT, } \\
6.3 \mathrm{~km}\end{array}$ & 600 at $6 \mathrm{~km}$ \\
\hline & $\begin{array}{c}662 \text { at } 4.2 \mathrm{~km} \\
1633 \mathrm{MDT}\end{array}$ & 600 at $4-4.5 \mathrm{~km}$ \\
\hline \multirow[t]{3}{*}{ First graupel } & at $5.8 \mathrm{~km}$ & at $5.8 \mathrm{~km}$ \\
\hline & 0.01 liter $^{-1}$ & 0.24 liter $^{-1}$ \\
\hline & 1623 MDT & $1626 \mathrm{MDT}$ \\
\hline \multirow{12}{*}{$\begin{array}{l}\text { Concentration of ice } \\
\text { particles }\left(1^{-1}\right)\end{array}$} & 0.55 at $6.4 \mathrm{~km}$ & 0.6 at $6 \mathrm{~km}$ \\
\hline & $\begin{array}{l}1620 \text { MDT, ice } \\
\text { crystals }\end{array}$ & $1620-1623 \mathrm{MDT}$ \\
\hline & 1 at $6 \mathrm{~km}$ & 5 at $6 \mathrm{~km}$ \\
\hline & 1625 MDT & $1625-1626 \mathrm{MDT}$ \\
\hline & 70 at $7 \mathrm{~km}$ & no observation \\
\hline & $1625 \mathrm{MDT}$ & \\
\hline & mainly $<1 \mathrm{~mm}$ & \\
\hline & 79 at $7.7 \mathrm{~km}$ & 30 at $5.3 \mathrm{~km}$ \\
\hline & 10 at $6 \mathrm{~km}$ & 1640-1641 MDT \\
\hline & $\begin{array}{l}1641 \mathrm{MDT} \\
\text { mainly }<1 \mathrm{~mm} \\
20 \text { at } 7-7.8 \mathrm{~km}\end{array}$ & mainly $<1 \mathrm{~mm}$ \\
\hline & $7-10$ at $6 \mathrm{~km}$ & \multirow{2}{*}{$\begin{array}{l}45-64 \text { at } 6 \mathrm{~km} \text {, } \\
1647-1651 \mathrm{MDT} \\
\text { mainly }<1 \mathrm{~mm}\end{array}$} \\
\hline & $\begin{array}{l}1649 \mathrm{MDT} \\
\text { mainly }<1 \mathrm{~mm}\end{array}$ & \\
\hline
\end{tabular}


At that time, the model cloud still consisted mainly of liquid hydrometeors. In its upper part, however, the air was subsaturated with respect to water but supersaturated with respect to ice. As observed, some ice particles (crystals), resulting from frozen drops, already existed with a maximum value of $0.55 \mathrm{~L}^{-1}$ at 6.4 $\mathrm{km}$ ASL (the King Air found a few tenths per liter at $6 \mathrm{~km}$ ASL during its first three passes between 1617 and 1623 MDT) (Table 2b).

At $1621 \mathrm{MDT}$, the maximum drop number concentration had reached $572 \mathrm{~cm}^{-3}$ at $6.3 \mathrm{~km}$ ASL. At that time, the King Air observed $600 \mathrm{~cm}^{-3}$ at $6 \mathrm{~km}$ ASL and no millimeter-sized ice particles. The liquid water content of the cloud at $6 \mathrm{~km}$ ASL had reached a value of about $2.7 \mathrm{~g} \mathrm{~kg}^{-1}\left(\approx 1.78 \mathrm{~g} \mathrm{~m}^{-3}\right)$, slightly larger than the values of $1-1.75 \mathrm{~g} \mathrm{~m}^{-3}$ measured by the King Air between 1620 and 1623 MDT (passes 2 and 3 ).

When the model cloud reached the $-20^{\circ} \mathrm{C}$ to $-25^{\circ} \mathrm{C}$ level, an explosive growth with maximum velocities up to $16.5 \mathrm{~m} \mathrm{~s}^{-1}$ (at $6.8 \mathrm{~km}$ and 1625 MDT) began. This phase started at $1621 \mathrm{MDT}$ and lasted till about 1633 MDT. The sailplane that ascended in the main updraft of the cloud reported maximum vertical velocities up to $15 \mathrm{~m} \mathrm{~s}^{-1}$ in the region of $6.5-7 \mathrm{~km}$ ASL between 1627 and 1629 MDT. Since the aircraft had to avoid the regions of high reflectivity, the vertical velocities probably had been higher than those observed. There was good agreement with observations both for the liquid cloud dimensions $(6-8 \mathrm{~km})$ and the mean width of the updraft core $(2 \mathrm{~km}$ diameter).

With a mean rise rate of $5-6 \mathrm{~m} \mathrm{~s}^{-1}$, the model cloud top reached its highest altitude of $11 \mathrm{~km}$ ASL within $10 \mathrm{~min}$. At 1629 MDT ( $t_{w}=29 \mathrm{~min}$ ) the maximum liquid water content of the primary cloud had already significantly decreased to about $0.4 \mathrm{~g} \mathrm{~kg}^{-1}$ $\left(\approx 0.26 \mathrm{~g} \mathrm{~m}^{-3}\right)$ between 6 and $7 \mathrm{~km} \mathrm{ASL}$ due to the rapid growth of graupel via riming. This decrease in the liquid water content was accompanied by an increase of the mixing ratio for graupel (Figs. 3a,b). The rapid weakening of the updraft and the liquid dry out of the actual observed cloud was estimated to begin between 1632 and 1634 MDT. This was simulated to occur several minutes earlier, between 1627 and 1629 MDT. The droplet size spectrum near the location of the maximum liquid water content of the main simulated cloud at 1629 MDT (Figs. 4a-c) was of continental type with one maximum near $10 \mu \mathrm{m}$ and a second near $8 \mu \mathrm{m}$. Notice that the main aerosol mass is associated with the main water mass. The drops larger than $20 \mu \mathrm{m}$ appeared in negligible concentration. This is in good agreement with the sailplane observations that found largest drops of $35 \mu \mathrm{m}$ in diameter at $6-7 \mathrm{~km}$ ASL in concentrations of $0.1-$ $1 \mathrm{~cm}^{-3}$. The sailplane ascending from 6 to $7 \mathrm{~km}$ ASL between 1627 and 1629 MDT observed liquid water contents as high as $2.5 \mathrm{~g} \mathrm{~m}^{-3}$, and even the King
Air-at $5.4 \mathrm{~km} \mathrm{ASL}$ - still observed $1.8 \mathrm{~g} \mathrm{~m}^{-3}$ (Table $2 b$ ).

The ice particle concentrations observed by the aircraft between 1625 and 1630 MDT ranged between 2 and $5 \mathrm{~L}^{-1}$ at a level near $6 \mathrm{~km}$ ASL. At the same level, the modeled number concentration of ice particles was $1 \mathrm{~L}^{-1}$, increasing to $70 \mathrm{~L}^{-1}$ at $7 \mathrm{~km}$ ASL. Unfortunately, no measurements were made at $7 \mathrm{~km}$ ASL. On the other hand, at later times our model predicted too low ice particle concentrations at $6 \mathrm{~km}$ and below. Thus, after 1641 MDT the observed total concentration of ice particles reached $30 \mathrm{~L}^{-1}$ at $5.3 \mathrm{~km}$ ASL and increased at $6 \mathrm{~km}$ ASL from a few $\mathrm{L}^{-1}$ up to 64 $\mathrm{L}^{-1}$ at $1648 \mathrm{MDT}$. However, at $1641 \mathrm{MDT}$ our model produced a maximum value of 79 ice particles $L^{-1}$ at $7.7 \mathrm{~km}$ ASL but only about $10 \mathrm{~L}^{-1}$ at $6 \mathrm{~km}$ ASL. This was still the case at 1649 MDT, when our model produced a maximum value of 20 ice particles $\mathrm{L}^{-1}$ between 7 and $7.8 \mathrm{~km}$ ASL and again only $7-10$ ice particles $\mathrm{L}^{-1}$ at $6 \mathrm{~km}$ ASL. We conclude that our model produced too low concentrations of ice particles along the penetration passes of the aircrafts after the onset of the rapid growth phase. Concentrations as high as measured by the aircrafts were only present in higher levels. The obvious reason for this fact is that we chose to produce ice particles in our model only by a simple drop-freezing mechanism. It is clear from many field observations that additional ice particles are formed by contact nucleation, by sorption of vapor on aerosol particles, and by ice multiplication mechanisms. All these were not considered in the present model, but some will be considered in future models.

Ice particles of millimeter size were observed for the first time by the King Air at $5.8 \mathrm{~km}$ ASL and 1626 MDT reaching a concentration of 0.24 per liter by 1630 MDT. As expected from our underprediction of the total ice particle concentration, our model predicted only $0.06 \mathrm{~L}^{-1}$ for graupel of size larger than $1 \mathrm{~mm}$ (Table $2 \mathrm{~b}$ ). Maximum graupel sizes of 4-7 mm diameter were observed both by the King Air and the sailplane around 5-6 km ASL between 1630 and 1651 MDT, in good agreement with the graupel sizes of $4-8 \mathrm{~mm}$ in diameter predicted by our model at 1641 MDT and $5 \mathrm{~km}$ ASL (Figs. 5a,b). From Fig. 5c, we note that the main aerosol mass follows the main graupel mass, a correlation mentioned earlier for the liquid phase. Liquid dry out in our model was completed around 1645-1650 MDT. This is in accordance with the observed negligible water content by about 1645 MDT (Table 2b). Rain falling from the model cloud began to reach the ground around 1645 MDT and lasted till about 1710 MDT. This is a few minutes later than observed and must be explained, perhaps by an overestimate of the effects of evaporation and an overestimate of the updraft that prevented the rain from reaching the ground. (This is illustrated in Fig. 7a in terms of the precipitation rate.) 

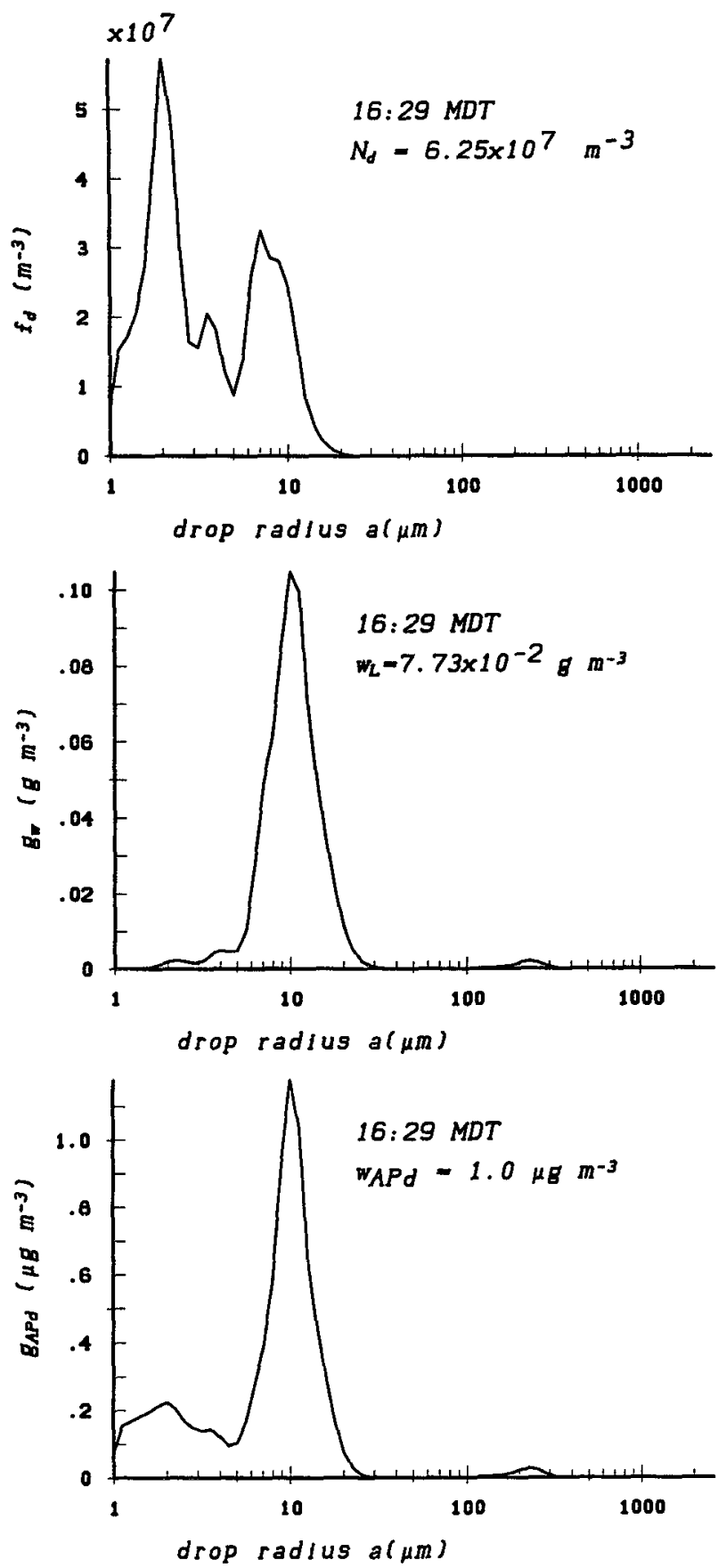

Fig. 4. For $X=18.6 \mathrm{~km}, Z=6925 \mathrm{~m}$ ASL, and for $1629 \mathrm{MDT}$ $\left(t_{w}=29 \mathrm{~min}\right)$ : (a) Number density distribution function of drops $f_{d}(a)$, $N_{d}=$ total number of drops. (b) Water mass density distribution function $g_{w}(a), w_{L}=$ liquid water content. (c) Aerosol mass density distribution function in drops $g_{A P d}(a), w_{A P d}=$ total $A P$ mass in drops. The density distribution functions are displayed per logarithmic radius interval.

\section{c. Comparison of present model with other models}

The results of the CCOPE field experiment were used by Helsdon and Farley (1987) to test a 2-dimen- sional Storm Electrification Model (SEM) and by Murakami (1990) to verify his 3-dimensional cloud model.
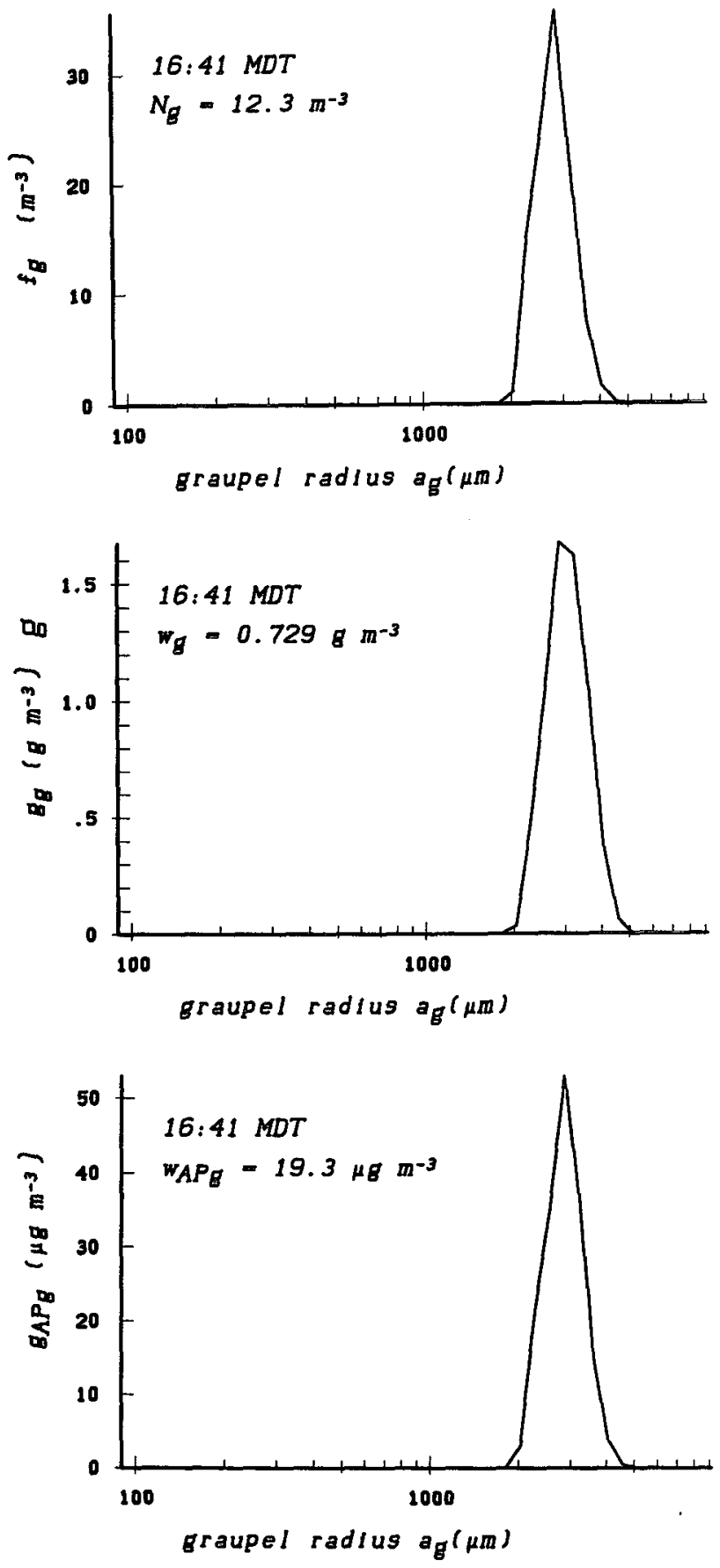

FIG. 5. For $X=18 \mathrm{~km}, Z=4925 \mathrm{~m}$ ASL, and for 1641 MDT $\left(t_{w}\right.$ $=41 \mathrm{~min}$ ). (a) Number density distribution function of graupel $f_{g}\left(a_{g}\right)$, $N_{s}=$ total number of graupel. (b) Graupel mass density distribution function $g_{g}\left(a_{g}\right), w_{g}=$ total mass of graupel. (c) Aerosol mass density distribution function within graupel $g_{A P_{g}}\left(a_{g}\right), w_{A P_{g}}=$ total $A P$ mass within graupel. The density distribution functions are displayed per logarithmic radius interval. 
The SEM by Helsdon and Farley (1987) is a deep convective, slab-symmetric and 2-dimensional timedependent model that was ultimately developed to simulate and explain the electrical evolution of a cloud. Liquid and ice hydrometeors are divided by bulk water parameterization into five classes (cloud water, cloud ice, rain, snow, and graupel/hail) with exponential size distributions hypothesized for the three precipitating classes. The primary cloud microphysical processes were simulated by the transformation of cloud water to rain via a Kessler parameterization and cloud water to snow via an approximation of the Bergeron-Findeisen process. Graupel and hail were formed by the aggregation of snow crystals, the capture of snow crystals, by rain water, or by heterogeneous drop freezing. The growth of hail took place in the dry and wet growth regimes. Convection was initiated by use of random perturbations in temperature and water vapor and a warm bubble.

In simulating the CCOPE case, a time correspondance was established based on the beginning of the rapid-growth phase. The model achieved good agreement in reproducing the cloud size, the cloud-top rise rate, the rapid-growth phase, the updraft structure, the first appearance of graupel, the cloud decay, and the location of hydrometeors with respect to updraft and downdraft structures. However, the SEM did not accurately model the cloud base height, which was lower than observed. The maximum vertical velocity of 26 $\mathrm{m} \mathrm{s}^{-1}$ found in the model could not be verified by aircraft observations since the aircraft had to avoid the regions of high reflectivity. The maximum cloud water mixing ratio appeared 2 min before the updraft maximum and exceeded the values observed. Simulated precipitation reached the ground at 1635 MDT, that is, earlier than observed. Of course, as expected from the microphysical parameterization of the model, the SEM could not predict any microphysical details such as the evolution of the drop spectrum, nor the size and concentration of the ice particles.

The three-dimensional, anelastic cloud model of Murakami (1990) also uses bulk water parameterized microphysics. Prognostic parameters are the number concentrations of ice and snow particles and the mixing ratios of six water species (water vapor, cloud water, cloud ice, rain, snow, and graupel/hail). The ice phase was initiated by deposition nucleation and by heterogeneous and homogeneous drop freezing. Conversion of cloud ice to snow was allowed to proceed by growth by diffusion and aggregation of ice crystals. Graupel was initiated through riming of snow crystals growing in the dry as well as in the wet growth mode. Convection was initiated by a warm, moist air bubble with excess temperature and moisture. Helsdon and Farley (1987) and Murakami (1990) established as time correspondence the beginning of the rapid-growth phase. His model simulated quite well the cloud-top height, the cloud size, the arrival time of precipitation at the cloud base, the first radar echo, the location of hydrometeors relative to updraft and downdraft structure, the number concentration of precipitating ice particles, the updraft velocity, and the cloud water content along the flight levels. On the other hand, the use of the original sounding as input led to a cloud base that was $1 \mathrm{~km}$ lower than observed. Also, the cloud-top ascent rate was higher than observed. Since aerosol scavenging is a strong function not only of the size of the aerosol particles but also of the size of the cloud particles, bulk water parameterization does not allow an accurate description of the wet deposition of air pollutants.

\section{d. Scavenging behavior of the model cloud}

The relatively good agreement between the simulated cloud microstructure and the observed microstructure motivated us to use our model to study two additional problems. 1) By including in our model the mechanisms that are responsible for aerosol particle scavenging, we determined the rate at which the scavenged aerosol mass was deposited on the ground and computed the concentration of the dissolved aerosol mass in the rain on the ground. 2) By purposely inhibiting ice nucleation, we attempted to study the effect of the presence of an ice phase on the microphysical and chemical evolution of the considered cloud.

As expected, the main dynamic features of the cloud evolving without ice were not significantly different from those of the cloud that evolved with ice. Again, the cloud formed at 1600 MDT with its base at $3.3 \mathrm{~km}$ ASL. After a moderate development, a rapid-growth phase started, and the overall maximum vertical velocity of $18.5 \mathrm{~m} \mathrm{~s}^{-1}$ at $6.8 \mathrm{~km} \mathrm{ASL}$ was reached $2 \mathrm{~min}$ earlier than for the cloud with ice (compare Fig. 6 with Fig. 3a). This higher vertical velocity was accompanied by a higher maximum liquid water content of 7.18 $\mathrm{g} \mathrm{kg}^{-1}$ that subsequently decreased to values lower than in the case with ice. The rapid decrease is due to the coalescence process forming precipitation-sized

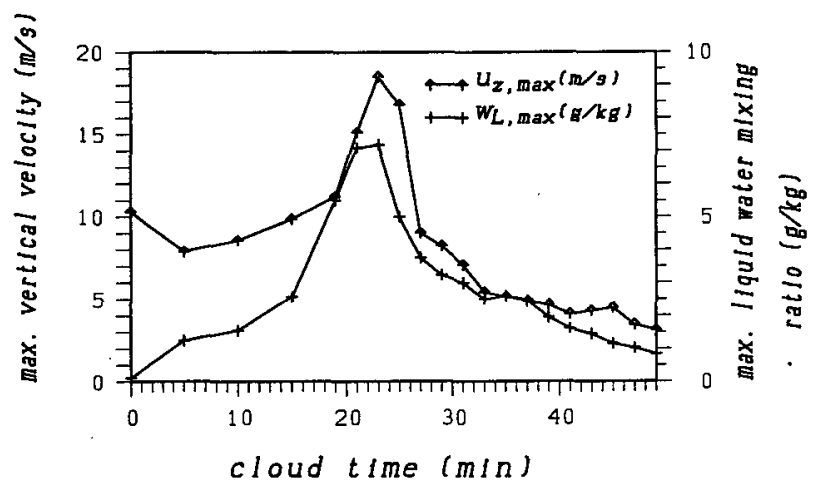

FIG. 6. Maximal vertical velocity $u_{z, \max }\left(\mathrm{m} \mathrm{s}^{-1}\right)$ and liquid water mixing ratio $w_{L, \max }\left(\mathrm{g} \mathrm{kg}^{-1}\right)$ for cloud with inhibited ice phase as function of cloud lifetime $t_{w}$ (min). 
drops. The cloud developed a similar width, but due to the higher vertical velocity the cloud top reached its highest level of $11 \mathrm{~km}$ ASL several minutes earlier than the case with ice. During the precipitation process the cloud base rose to $6 \mathrm{~km}$ ASL, and the average area covered by precipitation on the ground was smaller than in the case with ice.

Significant differences between the two model clouds showed up with respect to the onset of precipitation, the duration of precipitation, the deposition rate of the scavenged aerosol material, and the concentration of the scavenged aerosol material in the rain on the ground. These differences are illustrated in Figs. $7 \mathrm{a}-\mathrm{c}$ in which the rain rate, the sulfur deposition rate, and the concentration of sulfate in the rainwater are plotted as a function of cloud time. We note for each model run that the rain rate and the deposition rate are in phase as expected, while the concentration of sulfate is a minimum at the time the rain rate is a maximum. This feature is often observed (Kins 1982) and is easily explained in terms of lower salt concentration in large drops, which are associated with the maximum precipitation rate. We also note from Figs. 7a,b that precipitation and deposition set in much earlier in the cloud without the presence of an ice phase than in the mixed ice-water cloud. This, of course, is a result of the collisional growth process, which in the all-water cloud is the only precipitation forming process. Growth by riming, on the other hand, has to await the presence of ice particles that by vapor diffusion must first grow to a critical size before riming may start ( see p. 496 in Pruppacher and Klett 1978). Also, Fig. 7a shows that the precipitation event lasts longer and produces lower precipitation rates for the mixed ice-water cloud. This appears to be due to a less efficient conversion of cloud water to rainwater via riming than via coalescence of drops and a less pronounced evaporation in the large regions of liquid dry out.

In order to improve our understanding of the fate of scavenged aerosol material we calculated the total processed material involved in the different mechanisms active for the specific cloud simulated. Since our model is only two-dimensional, such calculations would apply only to a "cloud slice." Nevertheless, to be able to estimate at least the order of magnitude of the processed material we approximated the three-dimensional cloud by a "cloud" of cylindrical volume of diameter $6 \mathrm{~km}$, given by rotating the slice $180^{\circ}$.

In Table 3, we have listed the resulting values for the cumulative mass of water vapor converted to cloud water, of rainwater deposited on the ground, of aerosol mass taken up by nucleation scavenging, of aerosol mass taken up by drops, ice crystals and graupel by impaction scavenging, and the total aerosol mass deposited by rain on the ground. These values are calculated for 127-min model time (72-min cloud lifetime) in the case of the mixed-phase cloud and for 104min model time (49-min cloud lifetime) for the cloud
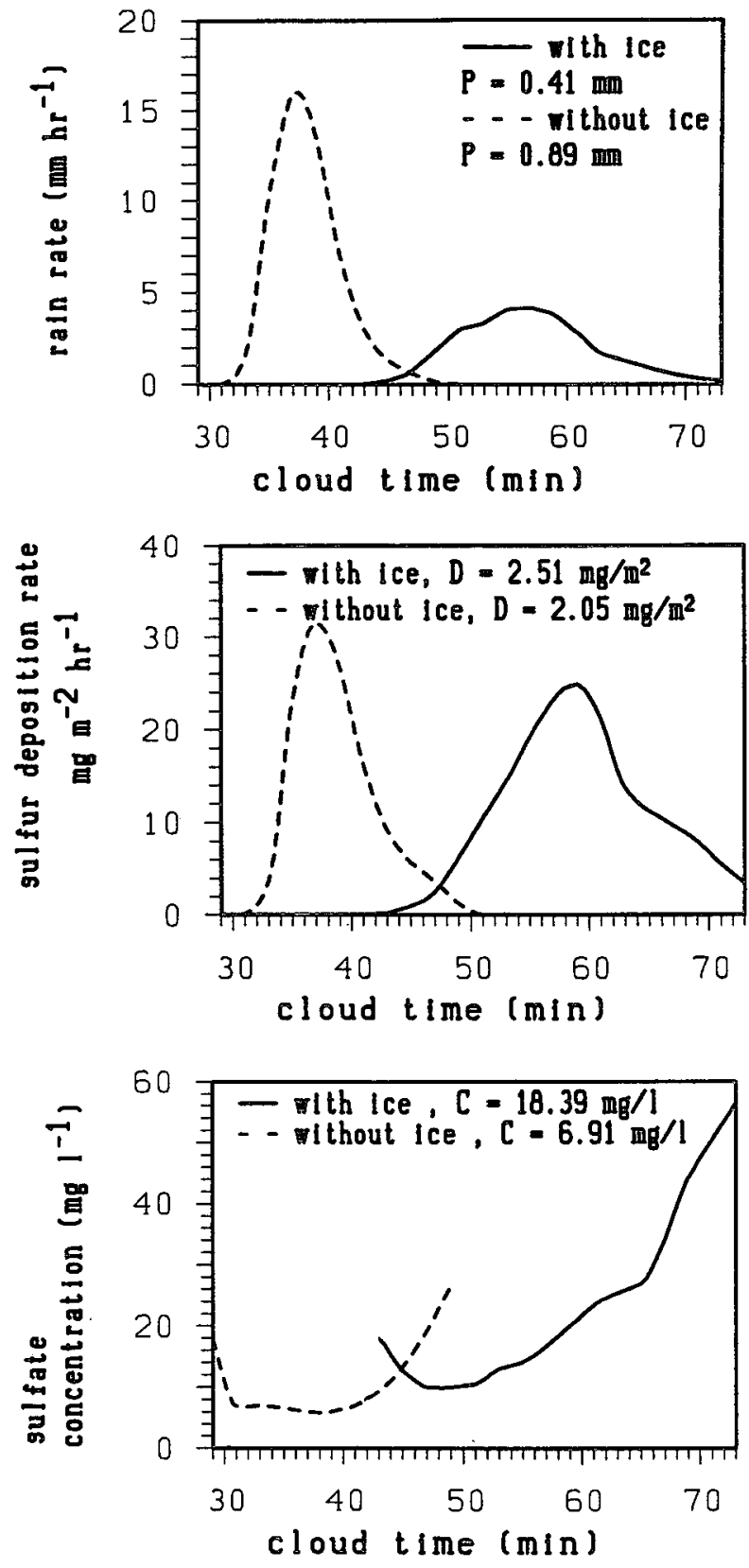

FIG. 7. (a) Rain rate $\left(\mathrm{mm} \mathrm{h}^{-1}\right)$, (b) sulfur deposition rate [mg $\left(\mathrm{m}^{2} \mathrm{~h}\right)^{-1}$, and (c) sulfate concentration $\left(\mathrm{mg} \mathrm{L}^{-1}\right)$ averaged over cloud domain for model run with ice (solid lines) and without ice (dashed lines); $P=$ cumulative precipitation $(\mathrm{mm}), D=$ cumulative sulfur deposition $\left(\mathrm{mg} \mathrm{m}^{-2}\right)$, and $C=$ precipitation-weighted mean sulfate concentration $\left(\mathrm{mg} \mathrm{L}^{-1}\right)$.

without ice. It should be noted here that a linear relationship between the numbers listed in Table 3 cannot be established since, except for the rainwater, the aerosol mass deposited by rain on the ground and the aerosol particle masses that are left in the different hydrometeors at the end of the simulation, the masses are subject to "recycling." We notice from Table 3a that 
due to the shorter lifetime of the all-water cloud and the higher saturation mixing ratio of water vapor with respect to ice, less vapor is converted to cloud water than in the water-ice cloud. This is also the cause for the smaller amount of aerosol taken up by nucleation scavenging in the all-water cloud [see Table 3c]. From Table $3 \mathrm{~b}$ we note that the total mass of rain deposited on the ground is higher for the all-water cloud than for the ice-water cloud. This is due to the higher efficiency with which cloud water is converted to rainwater in the all-water cloud under otherwise similar conditions. This may be a result of the fact that in the all-water cloud more cloud particles have the opportunity to grow to precipitation size by coalescence than in a cloud where precipitation involves only graupel. From Table 3d, we notice that the amount of aerosol taken up by impaction scavenging involving drops is less for the ice-water cloud than for the all-water cloud simply because liquid dry out in the ice-water cloud prevented impaction scavenging on the drops later during the cloud cycle and gave ample opportunity to impaction of aerosol particles on the falling graupel. This effect

TABLE 3. Cumulative processed material for the present cloud of 6-km average width (cloud volume equivalent to a cloud of cylindrical shape).

\begin{tabular}{|c|c|c|}
\hline $\begin{array}{l}\text { Cumulative processed material at the } \\
\text { end of simulation }\end{array}$ & $\begin{array}{l}\text { With ice } \\
(\mathrm{kg}) \text { after } \\
127 \mathrm{~min}\end{array}$ & $\begin{array}{l}\text { Without ice } \\
\text { (kg) after } \\
104 \text { min }\end{array}$ \\
\hline
\end{tabular}

(a) Mass of vapor converted to cloud water

(b) Mass of rainwater deposited on the ground

(c) Aerosol mass taken up by nucleation scavenging

(d) Aerosol mass taken up by impaction scavenging through drops

(e) Aerosol mass taken up by impaction scavenging through ice crystals

(f) Aerosol mass taken up by impaction scavenging through graupel

(g) Aerosol mass deposited by rain on the ground

$2.31 \times 10^{8} \quad 1.86 \times 10^{8}$

$2.43 \times 10^{7} .4 .12 \times 10^{7}$

$11100 \quad 10626$

$704 \quad 1099$

(h) Aerosol mass released into air due to total evaporation of graupel

(i) Aerosol redistributed to the liquid phase by complete melting of graupel

(k) Aerosol mass released into the air due to evaporation of drops

(l) Total aerosol mass taken up by graupel due to riming

(m) Aerosol mass remaining in drops, ice crystals, and graupel

(n) Aerosol mass redistributed via drop freezing

1807
TABLE 4. Precipitation and scavenging efficiencies computed from Eqs. (3)-(5) for the case where the ice phase in the model is (a) included and (b) excluded.

\begin{tabular}{ccc}
\hline \hline Efficiency & $\begin{array}{c}\text { CCOPE (a) } \\
\text { with ice }\end{array}$ & $\begin{array}{c}\text { CCOPE (b) } \\
\text { without ice }\end{array}$ \\
\hline$E_{1}$ & $10.7 \%$ & $22.5 \%$ \\
$E_{2}$ & $67.7 \%$ & $90.6 \%$ \\
$E_{3}$ & $17.2 \%$ & $15.4 \%$ \\
\hline
\end{tabular}

is the cause for the larger mass of aerosol taken up by impaction scavenging involving graupel (Table $3 \mathrm{f}$ ).

At first sight it is puzzling that the amount of aerosol redistributed to the ice phase via impaction scavenging (Table 3f) and riming (Table 31) is larger than the total $A P$ mass deposited by rain on the ground (Table $3 \mathrm{~g}$ ). It was established by observation and our model that precipitation in the ice-water cloud was due to the graupel only. One would therefore expect that a comparable amount of aerosol material would be deposited on the ground if all graupel had melted. However, only $2816 \mathrm{~kg}$ (Table $3 \mathrm{~g}$ ) were deposited on the ground by melted graupel. Our computations show that at the final phase of the cloud cycle under investigation about 2238 $\mathrm{kg}$ of aerosol material were released into the air due to evaporation of graupel (Table $3 \mathrm{~h}$ ), $3025 \mathrm{~kg}$ of aerosol material were redistributed by complete melting of graupel into the liquid present as rainwater (Table 3i), about $10461 \mathrm{~kg}$ of aerosol material were released into the air by evaporation of drops (Table $3 \mathrm{k}$ ) and about $1279 \mathrm{~kg}$ of aerosol mass remained still in small drops and ice particles (Table $3 \mathrm{~m}$ ) in the cloud by the time the cloud modeling was stopped. Considering these values and the fact that the aerosol particles are subject to multiple processes that all add to the cumulative masses, we consider that the aerosol mass deposited on the ground by melted graupel is reasonable.

Following Flossmann (1991) we define the following three efficiencies that describe the various conversion mechanisms:

$$
\begin{gathered}
E_{1}=\frac{\text { cumulative rain mass on ground }}{\text { cumulative water mass }} \text { converted from the vapor } \\
E_{2}=\frac{\text { cumulative } A P \text { mass }}{\text { scavenged by nucleation }} \\
\begin{array}{c}
\text { cumulative } A P \text { mass scavenged } \\
\text { by nucleation and impaction }
\end{array}
\end{gathered}
$$

cumulative $A P$ mass

$$
E_{3}=\frac{\text { deposited by the rain }}{\text { cumulative } A P \text { mass scavenged }} \text { by nucleation and impaction } .
$$

Efficiency values are shown in Table 4, based on numbers presented in Table 3 . We notice that for the 
cloud under study, the precipitation efficiency $E_{1}$ was quite low and lower for the case with ice than without ice. The higher efficiency for the case without ice is due to the higher deposition of rainwater on the ground; this formation of rainwater was due to a very efficient collision-coalescence process.

The values for $E_{2}$ show that nucleation scavenging is the dominant scavenging mechanism for deep convective clouds, in agreement with our earlier conclusions (Flossmann et al. 1985; Flossmann and Pruppacher 1988; Flossmann 1991). Since the dimensions of the clouds were quite similar in both cases, the nucleation rates were similar too, but the additional impaction scavenging by graupel leads to a smaller value of $E_{2}$ in the case with ice than in the case without ice. Probably, impaction scavenging of graupel has been overestimated by our model. Because of the lack of data available for the collision efficiencies for the $A P$ graupel interaction, we used the same efficiencies as for $A P$-drop collision process, thus handling the surface of the graupel as a liquid layer.

We further note that, in fair agreement with our earlier conclusions (Flossmann and Pruppacher 1988), $E_{3}$ is within a few percent given by $E_{1}$, though this relationship was expected to be closer based on the cloud studies of Flossmann and Pruppacher (1988) and Flossmann (1991), who considered warm marine clouds with tops reaching 3-4 km above sea level and a vertical extension of $2-3 \mathrm{~km}$. The clouds in the present study had vertical dimensions of approximately 6$7 \mathrm{~km}$ and reached levels of $11 \mathrm{~km}$ ASL. The differences imply that the efficiency of aerosol material deposition on the ground is not only controlled by the efficiency with which vapor is converted to rainwater but also by the distribution of the nucleated and scavenged aerosol material onto the different hydrometeors.

\section{Summary and conclusions}

The present study has used a two-dimensional cloud dynamics model in which we have included detailed microphysics for the water as well as for the ice phase. The model was tested for an observationally well documented cloud and precipitation event that occurred on 19 July 1981 near Miles City, during the CCOPE field experiment. Despite that observations were not always available at the exact model times nor at the exact model levels, our comparison between the predictions of our model and the observations allowed the following conclusions:

1) Very satisfactory agreement between model prediction and observations was obtained for the cloudtop height, the mean cloud diameter, the updraft width, the start of the vigorous-growth phase, the vertical velocities, the mean rise rate of the cloud top, the beginning and the end of the liquid dry out, and the maximum rainfall rate. The cloud base height was somewhat underestimated.
2) The model was able to predict the evolution of the cloud drop spectrum and the ice particle spectrum as a function of time. Model predictions were at least qualitatively in agreement with observations given the very limited possibilities for comparison (see Table $2 b$ ). The most significant discrepancy between model prediction and observation pertains to the appearance of ice particles whose concentration is highly underestimated by the model at low cloud levels. We suggest that this result is a consequence of not considering ice multiplication processes.

3) Comparison of our cloud model with bulk parameterized models shows that the parameterized models correctly describe most of the overall features of the Montana clouds but miss details of the cloud microstructure that can only be obtained if the time evolution of the size distribution of the cloud and precipitation particles is followed. Since the scavenging of aerosol particles as well as of gases is a strong function of the size of the evolving cloud and precipitation particles, parameterized models are prone to miss significant details of the cloud chemical features.

4) The presence of an ice phase in a cloud significantly affects both the cloud microstructure as well as the precipitation chemistry. Significant errors will be introduced in describing the time evolution of a cloud and its precipitation chemistry if the cloud that does contain an ice phase is modeled by assuming only liquid phase microphysics and the associated chemistry.

Acknowledgments. The present research was funded by the Ministery for Research and Technology of the Federal Republic of Germany under Project 3254007 0704580. The authors acknowledge with gratitude the financial support of the German National Science Foundation under Project SFB 233. The authors of this paper are solely responsible for its content.

\section{REFERENCES}

Alheit, R. R., 1991: Die Erweiterung und Anwendung eines 2-dimensionalen konvektiven Wolkenmodelles mit spektraler Berschreibung der Mikrophysik zur Untersuchung von Auswascheffekten unter Beruecksichtigung der Eisphase. Ph.D. thesis, Johannes Gutenberg-University Mainz, 293 pp.

- A. I. Flossmann, and H. R. Pruppacher, 1990: A theoretical study of the wet removal of atmospheric pollutants. Part IV: The uptake and redistribution of aerosol particles through nucleation and impaction scavenging by growing cloud drops and ice particles. J. Atmos. Sci., 47, 870-887.

Barklie, R. H. D., and N. R. Gokhale, 1959: The freezing of supercooled water drops. Stormy Weather Group Scientific Rep. MW-30, McGill University, Montreal, Canada.

Clark, T. L., 1977: A small scale dynamic model using a terrainfollowing coordinate transformation. J. Comput. Phys., 24, $186-215$.

- 1979: Numerical simulations with a three-dimensional cloud model. J. Atmos. Sci., 36, 2191-2215.

- and R. Gall, 1982: Three dimensional numeric model simulations of air flow over mountainous terrain: A comparison with observation. Mon. Wea. Rev., 110, 766-791. 
- , and R. D. Farley, 1984: Severe downslope windstorm calculations in two and three spatial dimensions using anelastic interactive grid nesting. J. Atmos. Sci., 41, 329-350.

Dye, J. E., J. J. Jones, W. P. Winn, T. A. Cerni, B. Gardiner, D. Lamb, R. L. Pitter, J. Hallett, and C. P. R. Saunders, 1986: Early electrification and precipitation development in a small, isolated Montana cumulonimbus. J. Geophys. Res., 91(D1), 1231-147.

Flossmann, A. I., 1991: The scavenging of two different types of marine aerosol particles calculated using a two-dimensional detailed cloud model. Tellus, 43B, 301-321.

, 1993: The effect of the impaction scavenging efficiency on the wet deposition by a convective warm cloud. Tellus, 45B, 3439.

_- 1994: A 2-D spectral model simulation of the scavenging of gaseous and particulate sulfate by a warm marine cloud. Atmos. Res., 32, 233-248.

removal of atmospheric pollutants. Part III: The uptake, redistribution, and deposition of $\left(\mathrm{NH}_{4}\right)_{2} \mathrm{SO}_{4}$ particles by a convective cloud using a two-dimensional cloud dynamics model. J. Atmos. Sci., 45, 1857-1871.

- W. D. Hall, and H. R. Pruppacher, 1985: A theoretical study of the wet removal of atmospheric pollutants. Part I: The redistribution of aerosol particles captured through nucleations and impaction scavenging by growing cloud drops. J. Atmos. Sci., 42, 582-606.

$\longrightarrow$, H. R. Pruppacher, and J. H. Topalian, 1987: A theoretical study of the wet removal atmospheric pollutants. Part II: The uptake and redistribution of $\left(\mathrm{NH}_{4}\right)_{2} \mathrm{SO}_{4}$ particles and $\mathrm{SO}_{2}$ gas simultaneously scavenged by growing cloud drops. J. Atmos. Sci., 44, 2912-2923.

Hall, W. D., 1980: A detailed microphysical model within a twodimensional dynamic framework: Model description and preliminary results. J. Atmos. Sci., 37, 2486-2507.

Helsdon, J. H., and R. D. Farley, 1987: A numerical modeling study of a Montana thunderstorm: 1. Model results versus observations involving nonelectrical aspects. J. Geophys. Res., 92(D5), 5645-5659
Hobbs, P. V., D. A. Bowdle, and L. F. Radke, 1985: Particles in the lower troposphere over the High Plains of the United States. Part I: Size distributions, elemental compositions and morphologies. J. Appl. Meteor., 24, 1344-1356.

Kins, L., 1982: Temporal variation of chemical composition of rainwater during individual precipitation events. Deposition of Atmospheric Pollutants, H.-W. Georgii and J. Pankrath, Eds., D. Reidel, 87-96.

Murakami, M., 1990: Numerical modelling of dynamical and microphysical evolution of an isolated convective cloud. The $19 \mathrm{July}$ 1981 CCOPE Cloud. J. Meteor. Soc. Japan, 68, 107-128.

Pruppacher, H. R., and J. D. Klett, 1978: Microphysics of Clouds and Precipitation. D. Reidel, 714 pp.

Rasmussen, R. M., and A. J. Heymsfield, 1987a: Melting and shedding of graupel and hail. Part I: Model physics. J. Atmos. Sci., 44, $2764-2763$.

- , and $-1987 \mathrm{~b}$ : Melting and shedding of graupel and hail. Part II: Sensitivity study. J. Atmos. Sci., 41, 374-380.

Smolarkiewicz, P. K., and T. L. Clark, 1985: Numerical simulation of the evolution of a three-dimensional field of cumulus clouds. Part I: Model description, comparison with observations and sensitivity studies. J. Atmos. Sci., 42, 502-522.

Taylor, G. R., 1989a: Sulfate production and deposition in midlatitude continental cumulus clouds. Part I: Cloud model formulation and base run analysis. J. Atmos. Sci., 46, 1971-1990.

__ 1989b: Sulfate production and deposition in midlatitude continental cumulus clouds. Part II: Chemistry model formulation and sensitivity analysis. J. Atmos. Sci., 46, 1991-2007.

Wang, P. K., and W. Ji, 1992: A numerical study of the diffusional growth and riming rates of ice crystals in cloud. Proc., 11th Int. Conf. on Clouds and Precipitation, Vol. 1, Montreal, Canada, International Commission on Clouds and Precipitation and International Association of Meteorology and Atmospheric Physics, 76-77.

WMO, 1988: Report of the Second International Cloud Modelling Workshop. Cloud Physics and Weather Modification Research Programme Tech. Document WMO/TD No. 268, WMP Report No. 11. 